\title{
Effect of sunlight on the physicochemical properties of refined bleached and deodorized palm olein
}

\author{
${ }^{1,3 *}$ Tonfack Djikeng, F., ${ }^{3}$ Womeni, H.M., ${ }^{2}$ Kingne Kingne, F., ${ }^{4}$ Karuna, M.S.L., ${ }^{4}$ Rao, \\ B.V.S.K. and ${ }^{4}$ Prasad, R.B.N. \\ ${ }^{1}$ School of Agriculture and Natural Resources, Catholic University Institute of Buea, P.O BOX 563, Buea, \\ Cameroon \\ ${ }^{2}$ School of Engineering, Catholic University Institute of Buea, P.O BOX 563, Buea, Cameroon \\ ${ }^{3}$ Department of Biochemistry, Faculty of Science, University of Dschang, P.O BOX 67, Dschang, Cameroon \\ ${ }^{4}$ CSIR-Indian Institute of Chemical Technology, Centre for Lipid Research, Tarnaka, Hyderabad 500007, \\ India
}

\begin{abstract}
Article history:
September 2018

Available Online: 28

September 2018

Keywords:

Palm olein,

Solar exposure,

Ambient storage,

Antioxidants,

Quality
\end{abstract}

Received: 16 July 2018

Received in revised form: 16

Accepted: 21 September 2018

DOI:

https://doi.org/10.26656/fr.2017.3(1).209

\begin{abstract}
In this study, the effect of sunlight on the quality of palm olein was assessed. Palm olein samples were subjected to sunlight $\left(34-40^{\circ} \mathrm{C}\right)$ and ambient storage $\left(\sim 24^{\circ} \mathrm{C}\right)$ for 90 days. Oil samples were collected at 30 days intervals for quality analysis. At the beginning of the experiment, the peroxide (PV), p-anisidine (p-AnV), total oxidation (TOTOX), thiobarbituric acid (TBA) and free fatty acid (FFA) values of palm olein were $2.67 \mathrm{ppm}$, $0.68,6.02,0.69$ and $0.07 \%$ respectively; color $1 \mathrm{R}, 6 \mathrm{Y}$ and induction time (IT) 23.89 and $26.55 \mathrm{~h}$ for oil-containing antioxidant and oil without antioxidants respectively. After 90 days storage at room temperature, the $\mathrm{PV}, p-\mathrm{An}-\mathrm{V}$, TOTOX, TBA and FFA values were respectively ranged between $5.19-7.13 \mathrm{ppm}, 1.27-2.99,11.65-17.25,0.97-1.73 \mathrm{ppm}$ and $0.11-0.12 \%$; the color in the red and yellow unit 1.17-1.19R and $6.00-6.10 \mathrm{Y}$ respectively; and the induction time 22.82-25.77 h. However, the same parameters after 90 days of exposure to sunlight were ranged in the same order, between $34.11-36.50 \mathrm{ppm}, 28.22$ $29.65,96.44-102.65,5.38-5.44 \mathrm{ppm}$ and $0.63-0.67 \%$ respectively; the color in the red and yellow units $0.20 \mathrm{R}$ and $0.77-0.80 \mathrm{Y}$ respectively; and the induction time $0.01 \mathrm{~h}$. Results showed that sunlight significantly reduced the quality of palm olein, even with the presence of antioxidants.
\end{abstract}

\section{Introduction}

Vegetable oils and fats are important components of our diet. From a nutritional point of view, they are excellent sources of energy and important vehicles of liposoluble vitamins in the human body. They are also good sources of essential fatty acids which are the precursors of important hormones, such as prostaglandins, and control many physiological factors such as blood pressure, cholesterol level and reproductive system (Walisiewicz-Niekbalska et al., 1997). However, they are chemically unstable due to the sensitivity to oxidation of their unsaturated fatty acids (Bruscatto et al., 2009). Different variables involved in oil shelf-life such as processing, storage conditions, light exposure, type of packaging material, availability of oxygen and addition of antioxidants affect the oxidative stability of oils and fats. Two famous mechanisms of oxidation of lipids are well known, autooxidation and photooxidation. Among these, autooxidation has been intensively studied; while photooxidation is generally neglected. Autooxidation through the free radical chain reaction via the attack on the alpha-methylene of the carbon double bonds of the unsaturated fatty acids is a slow process which requires a long time to produce a sufficient amount of peroxides and develop unpleasant flavors in lipid containing products (Naz et al., 2004). On the other hand, photooxidation which involves extremely electrophilic singlet oxygen on the unsaturated fatty acids, resulting in the formation of peroxy radicals and finally hydroperoxides, is a very fast reaction, with a rate of at least 1000-1500 times faster than that of autooxidation (Cuppett et al., 1997). When one of these reactions is taking place in the oil, it can lead to a significant loss of its quality in both sensorial (rancidity) and nutritional values (loss of polyunsaturated fatty acids and vitamins), bringing about chemical spoilage and also produces free radicals and reactive oxygen species which 
are reportedly associated with carcinogenesis, mutagenesis, inflammation, ageing and cardiovascular diseases (Siddhuraju and Becker, 2003). When oxidized oils are incorporated in foods, co-oxidation reactions can also be initiated, leading to the loss of essential amino acids and reduction of protein digestibility (Cuvelier and Maillard, 2012). In order to limit these alterations, synthetic antioxidants such as butylated hydroxytoluene, butylated hydroxyanisole and ter-butylhydroquinone are generally added in oils (Womeni et al., 2013).

In many developing countries, especially in local markets, for advertising purposes or because of the lack of space in the shops, shopkeepers and retail wholesellers intentionally keep their oils and fats (packed in translucent polyethylene bottles) outside their shops, thus directly exposing them to sunlight. Such lack of control in the practice for storage and shipping of vegetable oils and fats prompts the commencement of photooxidation in a silent way (Anwar et al., 2007). Generally, it is well known that commercialized oils and fats contain synthetic antioxidants, which have been reported in many studies to be efficient towards autooxidation of lipid. However, their efficiency towards the sunlightcatalyzed photooxidation of vegetable oils and fats has not yet been intensively investigated.

Palm olein is generally prone to have a good oxidative stability. Its auto-oxidation during storage in the oven and ambient temperature has already been reported (Pimpa et al., 2009; Womeni et al., 2016), but no report is available on the effect of sunlight on the quality and oxidative stability of this oil. In Cameroon and other developing countries where palm oil and its derivatives (case of palm olein) are the most produced and consumed refined oil, the exposition of oil out from the shops for advertising purpose is highly applied. This exposure can significantly reduce the quality of the oil. The objective of this study was to evaluate the impact of sunlight radiations on the quality of palm olein, in comparison to ambient storage.

\section{Materials and methods}

\subsection{Materials}

Refined, bleached, and deodorized palm olein (RBD palm olein), free from additives was obtained from SCS/ RAFCA Palm Oil Industry Company Ltd, Bafoussam, West-Cameroon. All the chemicals and reagents used were of analytical reagent grade.

\subsection{Methods}

\subsubsection{Sample preparation and storage}

Two sets of RBD palm olein samples packed in $100 \mathrm{~mL}$ identical translucent borosil glass bottles, each of 8 bottles were prepared. Each set was also divided into two subsets of four bottles containing butylated hydroxytoluene as antioxidant at its legal concentration limit of $200 \mathrm{ppm}$, and the others without additives. Oils were introduced in the bottles and locked with their respective caps, in order to limit the effect of oxygen. One set of sample (eight bottles: four with additive and four without additives) was stored in the dark at room temperature (at around $24^{\circ} \mathrm{C}$ ) and the other under sunlight ( $8 \mathrm{~h}$ exposure per day for 90 consecutive days) (only during the day), from July, 16, 2015 to October, 16,2015 . The mean values for maximum and minimum temperature $\left({ }^{\circ} \mathrm{C}\right)$ for the months of July, August, September and October were $41.31 \pm 1.57,39.54 \pm 1.63$ (Average 40.46); 42.22 $\pm 1.87, \quad 36.33 \pm 1.11$ (Average 39.27) and 40.22 $\pm 1.87,28.77 \pm 3.23$ (Average 34.49) respectively. After every 30 days of storage (one month), one bottle of each sub-set was taken, and the oil was directly analyzed by measuring changes in color, quality indexes and induction time.

\subsubsection{Measurement of color}

The changes in color of palm olein samples during the storage were measured using a 1 - inch cell on a Lovibond Tintometer according to the official method of AOCS Cc 13e-92. (AOCS, 2003).

\subsubsection{Measurement of oxidation parameters}

Peroxide value was determined following the spectrophotometrical IDF standard method, 74A: 1991 (IDF, 1991). P-anisidine and free fatty acids values assays were carried out according to the procedure of AOCS Official Method CD 18-90 and CD 1-25 respectively (AOCS, 2003). Total oxidation (TOTOX) values were calculated using the equation TOTOX = $2 \mathrm{PV}+\mathrm{AnV}$ according to Shahidi and Wanasundara (2008). Thiobarbituric acid value was evaluated as described by Draper and Hadley (1990).

\subsubsection{Changes in the induction time during the storage}

Induction times of palm olein samples were determined using an automated Metrohm Rancimat instrument (Model 892). Each oil sample ( $\geq 5 \mathrm{~g}$ ) was separately weighted in a Rancimat test tube. The instrument was switch on and the heating block temperature set at $110^{\circ} \mathrm{C}$. After reaching the $110^{\circ} \mathrm{C}$, the measuring vessels filled with $60 \mathrm{Ml}$ deionized water were connected to the instrument via electrodes. The tubes containing the sample were sealed using the appropriate caps, and connected to both instrument and measuring vessels via the appropriate cables. After starting the gas flow $(20 \mathrm{~L} / \mathrm{h})$, the reaction tubes were individually placed in their respective heating blocks and 
the reaction started. Induction time, the time elapsed from the beginning until the oil starts to become rancid was automatically recorded by the instrument.

\subsection{Statistical analysis}

Results obtained in the present study were subjected to one-way analysis of variance (ANOVA) with Dunnet and Student-Newman-Keuls tests using GraphPad-InStat version 3.05, to evaluate the statistical significance of the data. A probability value at $\mathrm{p}<0.05$ was considered statistically significant.

\section{Results and discussion}

\subsection{Changes in color}

Changes in the color of palm olein samples during the storages are presented in Table 1 (A-B). It is clearly observed that at the beginning, the oil color was $1 \mathrm{R}, 6 \mathrm{Y}$. After the 90 days storage at room temperature, a significant increase $(\mathrm{p}<0.05)$ in color of oil samples with and without antioxidants $(1.17 \mathrm{R}, 6.02 \mathrm{Y}$, and $1.19 \mathrm{R}$, $6.00 \mathrm{Y}$ respectively) was registered. No significant difference was observed between the changes in the color of palm olein with and without butylated hydroxytoluene from the beginning today 90 during the storage at room temperature. However, compared to the initial color value $(1 \mathrm{R}, 6 \mathrm{Y})$, the color of oil samples stored under sunlight has significantly decreased $(\mathrm{p}<0.001)$ to $0.20 \mathrm{R}, 0.80 \mathrm{Y}$ for palm olein without antioxidant and $0.20 \mathrm{R}, 0.77 \mathrm{Y}$ for that supplemented with BHT after 90 days storage. No significant difference $(p>0.05)$ in color change was registered between both samples during the storage under sunlight, but, compared to the same samples stored at room temperature, they were significantly low $(p<0.001)$. The significant decrease in oil color stored under sunlight compared to the initial and oil samples stored at room temperature can be attributed to the destruction of pigments present in oil by sunlight radiations. These results are supported by the findings of Kim and Choe (2012), who showed that during photooxidation of the mixture of olive and perilla oils, chlorophyll b which was $4 \mathrm{mg} / \mathrm{kg}$ in oil at the initial, became lesser than $0.5 \mathrm{mg} / \mathrm{kg}$ after $48 \mathrm{~h}$ storage under light and between $3.5-4 \mathrm{mg} / \mathrm{kg}$ for those stored in dark at room temperature. This means that light can completely destroy the pigments in oil, leading to the reduction of its color. However, these results are not in agreement with those of Anwar et al. (2007) and Raza et al. (2009) who showed no significant change $(p>0.05)$ in color of soybean and sunflower oils respectively, during the storage after 90 days and 7 weeks storages respectively in the dark and under sunlight.

\subsection{Changes in peroxide value}

Peroxide value is generally used for measuring the primary oxidation state of oil, indicating the amount of hydroperoxides formed during its alteration (Ozkan et al., 2007). The changes in peroxide values of palm olein with and without additives during the 90-day storage in the dark at room temperature and under sunlight are presented in Table 2 (A-B). Generally, the peroxide values in all the oil samples were increasing during the storage. Initially, the peroxide value of palm olein was $2.67 \mathrm{ppm}$, which was in the accepted range as recommended by the regulation $(<10 \mathrm{ppm})(\mathrm{FAO} / \mathrm{WHO}$, 2009). After the 90 day storage in the dark at room temperature, the value increased up to 5.19 and $7.13 \mathrm{ppm}$ for palm olein supplemented with BHT and that without antioxidant respectively, and was still in the accepted range. The difference between these two samples might

Table 1A. Changes in color of palm olein without antioxidant under different storage conditions

\begin{tabular}{|c|c|c|c|c|}
\hline \multirow{3}{*}{ Storage time (Days) } & \multicolumn{4}{|c|}{ Palm olein } \\
\hline & \multicolumn{2}{|c|}{ Ambient storage } & \multicolumn{2}{|c|}{ Sunlight storage } \\
\hline & Red unit & Yellow unit & Red unit & Yellow unit \\
\hline 0 & $1.00 \pm 0.01 \mathrm{R}_{\mathrm{A}}^{\mathrm{a}}$ & $6.00 \pm 0.00 \mathrm{Y}^{\mathrm{a}^{\prime}} \mathrm{A}^{\prime}$ & $1.00 \pm 0.01 \mathrm{R}_{\mathrm{A}}^{\mathrm{a}}$ & $6.00 \pm 0.00 \mathrm{Y}^{\mathrm{a}^{\prime}} \mathrm{A}^{\prime}$ \\
\hline 30 & $1.00 \pm 0.00 \mathrm{R}_{\mathrm{A}}^{\mathrm{a}}$ & $6.00 \pm 0.01 \mathrm{Y}^{\mathrm{a}}{ }^{\prime}{ }^{\prime}$ & $0.21 \pm 0.00 \mathrm{R}_{\mathrm{B}}^{\mathrm{b}}$ & $1.50 \pm 0.01 \mathrm{Y}^{\mathrm{b}}{ }_{\mathrm{B}}$ \\
\hline 60 & $1.10 \pm 0.00 \mathrm{R}_{\mathrm{B}}^{\mathrm{a}}$ & $6.00 \pm 0.02 \mathrm{Y}^{\mathrm{a}^{\prime}}{ }_{\mathrm{A}^{\prime}}$ & $0.20 \pm 0.00 \mathrm{R}_{\mathrm{B}}^{\mathrm{b}}$ & $1.00 \pm 0.00 \mathrm{Y}^{\mathrm{b}^{\prime}}{ }_{\mathrm{C}}$ \\
\hline 90 & $1.17 \pm 0.01 \mathrm{R}^{\mathrm{a}}{ }_{\mathrm{C}}$ & $6.02 \pm 0.00 \mathrm{Y}^{\mathrm{a}^{\prime}} \mathrm{A}^{\prime}$ & $0.20 \pm 0.00 \mathrm{R}^{\mathrm{b}}{ }_{\mathrm{B}}$ & $0.80 \pm 0.01 \mathrm{Y}^{\mathrm{b}}{ }_{\mathrm{D}}$ \\
\hline
\end{tabular}

Table 1B. Changes in color of palm olein supplemented without BHT under different storage conditions

\begin{tabular}{|c|c|c|c|c|}
\hline \multirow{3}{*}{ Storage time (Days) } & \multicolumn{4}{|c|}{ Palm olein + BHT } \\
\hline & \multicolumn{2}{|c|}{ Ambient storage } & \multicolumn{2}{|c|}{ Sunlight storage } \\
\hline & Red unit & Yellow unit & Red unit & Yellow unit \\
\hline 0 & $1.00 \pm 0.01 \mathrm{R}_{\mathrm{A}}^{\mathrm{a}}$ & $6.00 \pm 0.00 \mathrm{Y}^{\mathrm{a}^{\prime}}{ }_{\mathrm{A}}$ & $1.00 \pm 0.01 \mathrm{R}_{\mathrm{A}}^{\mathrm{a}}$ & $6.00 \pm 0.00 \mathrm{Y}^{\mathrm{a}^{\prime}}{ }_{\mathrm{A}^{\prime}}$ \\
\hline 30 & $1.00 \pm 0.00 \mathrm{R}_{\mathrm{A}}^{\mathrm{a}}$ & $5.97 \pm 0.01 \mathrm{Y}^{\mathrm{a}^{\prime}}{ }_{\mathrm{A}}$ & $0.20 \pm 0.00 \mathrm{R}_{\mathrm{B}}^{\mathrm{b}}$ & $1.54 \pm 0.00 \mathrm{Y}^{\mathrm{b}^{\prime}}{ }_{\mathrm{B}}{ }^{\prime}$ \\
\hline 60 & $1.08 \pm 0.00 \mathrm{R}_{\mathrm{B}}^{\mathrm{a}}$ & $6.00 \pm 0.00 \mathrm{Y}^{\mathrm{a}^{\prime}}{ }_{\mathrm{A}}$ & $0.20 \pm 0.00 \mathrm{R}_{\mathrm{B}}^{\mathrm{b}}$ & $1.00 \pm 0.00 \mathrm{Y}^{\mathrm{b}^{\prime}}{ }_{\mathrm{C}}$ \\
\hline 90 & $1.19 \pm 0.00 \mathrm{R}_{\mathrm{C}}^{\mathrm{a}}$ & $6.00 \pm 0.00 \mathrm{Y}^{\mathrm{a}}{ }_{\mathrm{A}}$ & $0.20 \pm 0.00 \mathrm{R}_{\mathrm{B}}^{\mathrm{b}}$ & $0.77 \pm 0.00 \mathrm{Y}^{\mathrm{b}^{\prime}}{ }_{\mathrm{D}}$ \\
\hline
\end{tabular}

Data are presented as mean $( \pm \mathrm{SD})(\mathrm{n}=3)$. $(\mathrm{a}-\mathrm{b})$ and (a'-b') Means within each row for each color with different superscripts are significantly different $(\mathrm{p}<0.05)$. (A-D) and (A'-D') Means within each column for each color with different superscripts are significantly $(\mathrm{p}<0.05)$ different. 
Table 2A. Changes in peroxide and anisidine values of palm olein under different storage conditions

\begin{tabular}{|c|c|c|c|c|}
\hline \multirow{3}{*}{ Storage time (Days) } & \multicolumn{4}{|c|}{ Palm olein } \\
\hline & \multicolumn{2}{|c|}{ Ambient storage } & \multicolumn{2}{|c|}{ Sunlight storage } \\
\hline & Peroxide value (meq $/ \mathrm{kg})$ & p-anisidine value & Peroxide value (meq/kg) & p-anisidine value \\
\hline 0 & $2.67 \pm 0.10_{\mathrm{A}}^{\mathrm{a}}$ & $0.68 \pm 0.00^{\mathrm{a}^{\prime}}$ & $2.67 \pm 0.10_{\mathrm{A}}^{\mathrm{a}}$ & $0.68 \pm 0.00^{\mathrm{a}^{\prime}} \mathrm{A}^{\prime}$ \\
\hline 30 & $2.90 \pm 0.10_{\mathrm{A}}^{\mathrm{a}}$ & $0.98 \pm 0.03^{\mathrm{a}^{\prime}}$ & $19.65 \pm 0.29^{b}{ }_{B}$ & $10.49 \pm 0.01^{c^{\prime}}{ }^{\prime}$ \\
\hline 60 & $5.35 \pm 0.20^{\mathrm{a}}{ }_{\mathrm{B}}$ & $2.46 \pm 0.05^{\mathrm{a}} \mathrm{C}^{\prime}$ & $21.17 \pm 0.60^{\mathrm{c}}{ }_{\mathrm{B}}$ & $24.81 \pm 0.11^{\mathrm{c}^{\prime}} \mathrm{C}^{\prime}$ \\
\hline 90 & $7.13 \pm 0.65^{\mathrm{a}}{ }_{\mathrm{C}}$ & $2.99 \pm 0.01^{\mathrm{a}}{ }^{\prime}$, & $36.50 \pm 0.66^{\mathrm{c}}{ }_{\mathrm{C}}$ & $29.65 \pm 0.02^{\mathrm{c}^{\prime}}{ }_{\mathrm{D}}$ \\
\hline
\end{tabular}

Table 2B. Changes in peroxide and anisidine values of palm olein supplemented with BHT under different storage conditions

\begin{tabular}{|c|c|c|c|c|}
\hline \multirow{3}{*}{ Storage time (Days) } & \multicolumn{4}{|c|}{ Palm olein + BHT } \\
\hline & \multicolumn{2}{|c|}{ Ambient storage } & \multicolumn{2}{|c|}{ Sunlight storage } \\
\hline & Peroxide value (meq $/ \mathrm{kg})$ & p-anisidine value & Peroxide value (meq/kg) & p-anisidine value \\
\hline 0 & $2.67 \pm 0.10_{\mathrm{A}}^{\mathrm{a}}$ & $0.68 \pm 0.00^{\mathrm{a}^{\prime}} \mathrm{A}^{\prime}$ & $2.67 \pm 0.10_{\mathrm{A}}^{\mathrm{a}}$ & $0.68 \pm 0.00^{\mathrm{a}} \mathrm{A}^{\prime}$ \\
\hline 30 & $2.71 \pm 0.21_{\mathrm{A}}^{\mathrm{a}}$ & $0.72 \pm 0.02^{\mathrm{b}}{ }_{\mathrm{B}}$ & $20.96 \pm 1.28^{\mathrm{b}}{ }_{\mathrm{B}}$ & $11.54 \pm 0.12^{\mathrm{d}^{\prime}}{ }_{\mathrm{B}}$ \\
\hline 60 & $3.08 \pm 0.00_{\mathrm{A}}^{\mathrm{b}}$ & $0.98 \pm 0.01^{\mathrm{b}}{ }_{\mathrm{C}}$ & $24.11 \pm 1.44_{B}^{\mathrm{d}}$ & $25.07 \pm 0.77_{C}^{\mathrm{d}^{\prime}}$ \\
\hline 90 & $5.19 \pm 0.17^{\mathrm{b}}$ & $1.27 \pm 0.00^{\mathrm{b}}{ }_{\mathrm{D}}^{\prime}$ & $34.11 \pm 1.98^{\mathrm{d}}{ }_{\mathrm{C}}$ & $28.22 \pm 2.22^{\mathrm{c}^{\prime}}$ \\
\hline
\end{tabular}

Data are presented as mean $( \pm \mathrm{SD})(\mathrm{n}=3)$. $(\mathrm{a}-\mathrm{d})$ and $\left(\mathrm{a}^{\prime}-\mathrm{d}^{\prime}\right)$ Means within each row for each parameter with different superscripts are significantly different $(\mathrm{p}<0.05)$. (A-D) and (A'-D') Means within each column for each parameter with different superscripts are significantly $(\mathrm{p}<0.05)$ different.

be attributed to the presence of antioxidants which have retarded the peroxide formation in oil by giving their hydrogen atoms, as reported by Womeni et al. (2016). Concerning the oil samples stored under sunlight, they have exhibited the highest peroxide values compared to those kept in the dark at room temperature. After 90 days of storage, their peroxide values were 36.50 and 34.11 ppm for oil enriched with BHT and that without antioxidant respectively, values which were about 6 folds the peroxide value of the same samples stored in the dark. Additionally, these values were significantly higher than $10 \mathrm{ppm}$ which is the highest recommended peroxide value of refined oils (FAO/WHO, 2009). This shows that peroxides are produced at a significant higher rate $(p<0.05)$ when oil is subjected to sunlight. These observations are in accordance with those of Anwar et al. (2007) and Raza et al. (2009) who reported a similar trend in peroxide values of soybean and sunflower oils respectively, stored under sunlight compared to the same oils kept in the dark at room temperature. In our study, the effect of BHT towards oil oxidation retardation under sunlight was not noticeable. Sunlight might lead to the complete destruction of the antioxidants.

\subsection{Changes in p-anisidine value}

$P$-anisidine value generally reflects the magnitude of the secondary oxidation state of oils and fats, by measuring their aldehydic products (Djikeng et al., 2017). The changes in $p$-anisidine value of palm olein samples are presented in Table 2 (A-B). As previously observed with the peroxide value, the $p$-anisidine value was increasing during both storages. The increase in $p$ anisidine value was significantly lower $(\mathrm{p}<0.05)$ in the dark at room temperature compared to sunlight. At the beginning of the experiment, the $p$-anisidine value of oil was 0.68. During the storage in the dark at room temperature, it was noticed that the $p$-anisidine value in oil without antioxidant was significantly increasing ( $>0.05$ ) compared to that of palm olein stabilized with BHT. At the $90^{\text {th }}$ day, this value was 2.99 in oil without BHT and 1.27 in that supplemented with that antioxidant. This could be attributed to the action of BHT as antioxidant, as it has been proven that by limiting peroxide formation in oils, their decomposition will also be delayed, so, secondary oxidation products formation will be less (Womeni et al., 2016). Compared to oil samples stored in the dark at room temperature, those exposed to sunlight have exhibited significantly higher $(\mathrm{p}<0.05) p$-anisidine values. The values were 29.65 and 28.22 respectively for palm olein without antioxidant and palm olein without additive, proof of their high secondary oxidation state. Their anisidine values were significantly higher than that recommended in fish oil, which is 20 . As previously seen with peroxide value, it is observed that aldehydic products were also produced at a significant higher rate $(p<0.05)$ when oil is subjected to sunlight. These results are in agreement with those of Anwar et al. (2007) and Raza et al. (2009) which have registered similar changes in $p$-anisidine values of soybean and sunflower oils respectively, stored under sunlight compared to the same oils kept in the dark at room temperature. Under sunlight, the effect of BHT in delaying secondary oxidation of palm olein oxidation was still not noticeable, due to the probable destruction of the antioxidant by sunlight radiations.

\subsection{Total oxidation (TOTOX value)}

The total oxidation state of palm olein samples subjected to dark at room temperature and sunlight is presented in Table 3 (A-B). A significant increase 
$(\mathrm{p}<0.05)$ in total oxidation was registered in all the samples compared to the initial value (6.02). The total oxidation under sunlight was very pronounced (102.65 and 96.44 for palm olein enriched with antioxidant and the same sample without additive respectively) compared to that of oils stored at room temperature (17.25 and 11.65 for palm olein without BHT and palm olein supplemented with BHT respectively). This shows the significant alteration of palm olein quality by sunlight compared to room temperature. At room temperature, the total oxidation value of palm olein without antioxidant was significantly higher $(p<0.05)$ than that containing BHT as antioxidant, this might be due to the ability of BHT to retard oxidation of oil by stabilizing free radicals. However, no difference $(p>0.05)$ has been registered in the total oxidation state of palm olein with and without antioxidants stored under sunlight during the complete period of experiment. So, sunlight is a big catalyst for oxidation of edible oils and fats. This is not surprising, as it has been reported that photooxidation is at least 1000 to 1500 times faster than autooxidation (Cuppett et al., 1997). Similar observations have been made in similar studies by other authors (Anwar et al., 2007; Raza et al., 2009).

\subsection{Changes in induction time of oil during the storages}

The Rancimat test is a technique based on the conductometric determination of volatile degradation products which is currently used for the evaluation of the oxidative stability of oils and fats as well as to the study of antioxidant potentiality of new molecules (Jain et al., 2005). Longer induction time indicates higher resistance to oxidation or good efficiency of the added antioxidants (Womeni et al., 2016). The changes in the induction period of stabilized and no stabilized palm olein samples are depicted in Table 3 (A-B). It is clearly seen that at the beginning (day 0 ), the induction time of palm olein without antioxidant (23.89) was significantly lower $(p<0.05)$ than that of the same oil supplemented with BHT $(26.55 \mathrm{~h})$. This can be attributed to the antioxidant activity of BHT. During the storage in the dark at room temperature, no significant change has been registered in the induction time of each oil compared to the initial values. Similar observations were made in oil samples exposed to sunlight, but here, a significant decrease $(p<0.05)$ in the induction period of both oil samples was registered and was almost zero at the $90^{\text {th }}$ day. No antioxidant activity of BHT was registered here. It is also important to mention that the induction periods of oil samples stored under sunlight were significantly lower $(p<0.05)$ than that of the same samples stored in the dark at room temperature. The decrement in the induction time of palm olein samples under sunlight reflects their high oxidative instability, due to the powerful destruction effect of oil by sunlight. These results are supported by those of peroxides $p$-anisidine and TOTOX which showed that oil samples subjected to sunlight were significantly altered, thus losing their resistance toward oxidation.

\subsection{Changes in thiobarbituric acid value}

Thiobarbituric acid assay is the most widely used method for the measurement of secondary oxidation products, which may contribute to off-flavour of oxidized oils (Iqbal and Bhanger, 2007). The relative increase in the thiobarbituric acid value of different palm olein samples in both storage conditions is presented in Table 4 (A-B). We can see that, palm olein samples

Table 3A. Changes in TOTOX value and Induction time of palm olein under different storage conditions

\begin{tabular}{|c|c|c|c|c|}
\hline \multirow{3}{*}{ Storage time (Days) } & \multicolumn{4}{|c|}{ Palm olein } \\
\hline & \multicolumn{2}{|c|}{ Ambient storage } & \multicolumn{2}{|c|}{ Sunlight storage } \\
\hline & TOTOX value & Induction time (h) & TOTOX value & Induction time (h) \\
\hline 0 & $6.02 \pm 0.20_{\mathrm{A}}^{\mathrm{a}}$ & $23.89 \pm 0.33^{\mathrm{a}^{\prime}}$ & $6.02 \pm 0.20_{\mathrm{A}}^{\mathrm{a}}$ & $23.89 \pm 0.33^{\mathrm{a}^{\prime}} \mathrm{A}^{\prime}$ \\
\hline 30 & $6.78 \pm 0.23^{\mathrm{a}}{ }_{\mathrm{A}}$ & $23.17 \pm 0.08^{\mathrm{a}^{\prime}} \mathrm{A}^{\prime}$ & $49.79 \pm 0.59^{\mathrm{b}}{ }_{\mathrm{B}}$ & $9.22 \pm 0.16^{\mathrm{c}^{\prime}}$ \\
\hline 60 & $13.16 \pm 0.45^{\mathrm{a}}{ }_{B}$ & $23.06 \pm 0.11^{\mathrm{a}^{\prime}}$, & $67.15 \pm 1.31^{\mathrm{c}}{ }_{\mathrm{C}}$ & $2.39 \pm 0.00^{\mathrm{c}^{\prime}} \mathrm{C}^{\prime}$ \\
\hline 90 & $17.25 \pm 1.31^{\mathrm{a}}{ }_{\mathrm{C}}$ & $22.82 \pm 0.01^{\mathrm{a}^{\prime}}{ }_{\mathrm{A}}$ & $102.65 \pm 1.34_{\mathrm{D}}^{\mathrm{c}}$ & $0.01 \pm 0.00^{\mathrm{c}^{\prime}}{ }_{\mathrm{D}}$ \\
\hline
\end{tabular}

Table 3B. Changes in TOTOX value and Induction time of palm olein supplemented with BHT under different storage conditions

\begin{tabular}{|c|c|c|c|c|}
\hline \multirow{3}{*}{ Storage time (Days) } & \multicolumn{4}{|c|}{ Palm olein + BHT } \\
\hline & \multicolumn{2}{|c|}{ Ambient storage } & \multicolumn{2}{|c|}{ Sunlight storage } \\
\hline & TOTOX value & Induction time $(\mathrm{h})$ & TOTOX value & Induction time $(\mathrm{h})$ \\
\hline 0 & $6.02 \pm 0.20_{\mathrm{A}}^{\mathrm{a}}$ & $26.55 \pm 0.77^{\mathrm{b}^{\prime}}$ & $6.02 \pm 0.20_{\mathrm{A}}^{\mathrm{a}}$ & $26.55 \pm 0.77^{\mathrm{b}^{\prime}}$ \\
\hline 30 & $6.14 \pm 0.44_{\mathrm{A}}^{\mathrm{a}}$ & $26.22 \pm 1.11^{\mathrm{b}}{ }_{\mathrm{A}}$ & $53.46 \pm 2.68^{\mathrm{b}}{ }_{\mathrm{B}}$ & $11.03 \pm 1.88^{\mathrm{c}{ }_{\mathrm{B}}}$ \\
\hline 60 & $7.14 \pm 0.01_{\mathrm{A}}^{\mathrm{b}}$ & $25.33 \pm 0.87^{\mathrm{b}} \mathrm{A}^{\prime}$ & $73.29 \pm 3.05^{\mathrm{d}}{ }_{\mathrm{C}}$ & $3.22 \pm 0.12^{\mathrm{c}^{\prime}}$ \\
\hline 90 & $11.65 \pm 0.34^{\mathrm{b}}{ }_{\mathrm{B}}$ & $25.77 \pm 1.55^{\mathrm{b}}{ }^{\prime}{ }^{\prime}$ & $96.44 \pm 6.18^{\mathrm{c}}{ }_{\mathrm{D}}$ & $0.01 \pm 0.00^{c^{\prime}}{ }^{\prime}{ }^{\prime}$ \\
\hline
\end{tabular}

Data are presented as mean $( \pm \mathrm{SD})(\mathrm{n}=3)$. (a-c) and (a'-c') Means within each row for each parameter with different superscripts are significantly different $(\mathrm{p}<0.05)$. (A-C) and (A'-C') Means within each column for each parameter with different superscripts are significantly $(\mathrm{p}<0.05)$ different. 
Table 4A. Changes in TBA and FFA values of palm olein under different storage conditions

\begin{tabular}{|c|c|c|c|c|}
\hline \multirow{3}{*}{ Storage time (Days) } & \multicolumn{4}{|c|}{ Palm olein } \\
\hline & \multicolumn{2}{|c|}{ Ambient storage } & \multicolumn{2}{|c|}{ Sunlight storage } \\
\hline & TBA value (ppm) & FFA value (mg KOH/g) & TBA value (ppm) & FFA value (mg KOH/g) \\
\hline 0 & $0.69 \pm 0.03_{\mathrm{A}}^{\mathrm{a}}$ & $0.07 \pm 0.00^{\mathrm{a}_{\mathrm{A}}}$ & $0.69 \pm 0.03^{\mathrm{a}}$ & $0.07 \pm 0.00^{\mathrm{a}^{\prime}}$ \\
\hline 30 & $0.89 \pm 0.01^{\mathrm{a}}{ }_{\mathrm{B}}$ & $0.09 \pm 0.00^{\mathrm{a}}{ }_{\mathrm{B}}$ & $0.96 \pm 0.00^{\mathrm{c}}{ }_{\mathrm{B}}$ & $0.20 \pm 0.00^{b^{\prime}}$ \\
\hline 60 & $1.13 \pm 0.00^{\mathrm{a}} \mathrm{C}$ & $0.10 \pm 0.00^{\mathrm{a}^{\prime}}{ }_{\mathrm{B}}$ & $1.55 \pm 0.01_{C}^{\mathrm{c}}$ & $0.60 \pm 0.02^{b^{\prime}}$ \\
\hline 90 & $1.73 \pm 0.00^{\mathrm{a}}{ }_{\mathrm{D}}$ & $0.12 \pm 0.01^{\mathrm{a}^{\prime}}$ & $5.38 \pm 0.06^{\mathrm{c}}{ }_{\mathrm{D}}$ & $0.67 \pm 0.02^{\mathrm{b}^{\prime}{ }_{\mathrm{D}}}$ \\
\hline
\end{tabular}

Table 4B. Changes in TBA and FFA values of palm olein supplemented with BHT under different storage conditions

\begin{tabular}{|c|c|c|c|c|}
\hline \multirow{3}{*}{$\begin{array}{l}\text { Storage time } \\
\text { (Days) }\end{array}$} & \multicolumn{4}{|c|}{ Palm olein + BHT } \\
\hline & \multicolumn{2}{|c|}{ Ambient storage } & \multicolumn{2}{|c|}{ Sunlight storage } \\
\hline & TBA value (ppm) & $(\mathrm{mg} \mathrm{KOH} / \mathrm{g})$ & TBA value (ppm) & FFA value $(\mathrm{mg} \mathrm{KOH} / \mathrm{g})$ \\
\hline 0 & $0.69 \pm 0.03_{\mathrm{A}}^{\mathrm{a}}$ & $0.07 \pm 0.00^{\mathrm{a}^{\prime}}{ }_{\mathrm{A}}$ & $0.69 \pm 0.03_{\mathrm{A}}^{\mathrm{a}}$ & $0.07 \pm 0.00^{\mathrm{a}^{\prime}} \mathrm{A}^{\prime}$ \\
\hline 30 & $0.65 \pm 0.01_{\mathrm{A}}^{\mathrm{b}}$ & $0.07 \pm 0.02^{\mathrm{a}^{\prime}} \mathrm{A}^{\prime}$ & $0.93 \pm 0.02^{\mathrm{ac}}{ }_{B}$ & $0.24 \pm 0.02^{b^{\prime}}$ \\
\hline 60 & $0.79 \pm 0.00^{\mathrm{b}}{ }_{\mathrm{B}}$ & $0.11 \pm 0.01^{\mathrm{a}} \mathrm{A}$ & $1.66 \pm 0.11_{C}^{\mathrm{c}}$ & $0.65 \pm 0.06^{\mathrm{b}}{ }_{C}$ \\
\hline 90 & $0.97 \pm 0.00^{\mathrm{b}}{ }_{\mathrm{C}}$ & $0.11 \pm 0.00^{\mathrm{a}} \mathrm{A}^{\prime}$ & $5.44 \pm 0.00^{\mathrm{c}}$ & $0.63 \pm 0.05^{b^{\prime}}$ \\
\hline
\end{tabular}

Data are presented as mean $( \pm \mathrm{SD})(\mathrm{n}=3)$. (a-c) and (a'-b') Means within each row for each parameter with different superscripts are significantly different $(\mathrm{p}<0.05)$. (A-C) and (A'-C') Means within each column for each parameter with different superscripts are significantly $(\mathrm{p}<0.05)$ different.

subjected to sunlight have exhibited significantly higher $(p<0.05)$ thiobarbituric acid values compared to those stored in the dark at room temperature. No significant change $(p>0.05)$ was registered in thiobarbituric acid values of palm olein supplemented and not supplemented with antioxidants and exposed to sunlight. This might be attributed to the loss of antioxidant activity of BHT due to its probable destruction by sunlight radiations. However, in the dark at room temperature, secondary oxidation of oil containing BHT was significantly lower $(p<0.05)$ than that free from antioxidants. This could be due to the efficiency of BHT against autooxidation of palm olein under this storage condition. These results are just confirming those previously obtained with $p$-anisidine value, showing the high secondary oxidation rate of palm olein subjected to sunlight compared to those kept dark at room temperature.

\subsection{Changes in free fatty acid value}

The formation of free fatty acids in oils and fats might be an important measure of their acidity. These fatty acids are released in oil due to the hydrolysis of triglycerides and may get promoted by reaction of oil with moisture (Freja et al., 1999). The changes in the free fatty acid profile of palm olein samples subjected to sunlight and dark at room temperature storages are reported in Table 4 (A-B). Initially, the free fatty acid value of palm olein was $0.07 \%$. This value was lower than that recommended by the Codex Alimentarius in refined oils $(0.2 \mathrm{mg} \mathrm{KOH} / \mathrm{g})(\mathrm{FAO} / \mathrm{WHO}, 2009)$. After the 90-day storage in the dark at room temperature, this value increased to 0.12 and $0.11 \mathrm{mg} \mathrm{KOH} / \mathrm{g}$, in palm olein without and with BHT respectively, which are still within the acceptable interval. Under sunlight, at the $90^{\text {th }}$ day, these values were 0.67 and $0.63 \mathrm{mg} \mathrm{KOH} / \mathrm{g}$ for palm olein without antioxidant and that with BHT respectively, showing a higher rate of hydrolysis in these oil samples under sunlight compared to dark at room temperature. These results are in accordance with those of Raza et al. (2009) and Anwar et al. (2007) who have made similar observations with sunflower and soybean oils stored at room temperature in the dark and under sunlight.

\section{Conclusion}

From the investigated oxidation parameters, it can be concluded that the exposure of palm olein to sunlight strongly promote its oxidative alteration at a significant higher rate, leading to the destruction of the oil quality (nutritional and organoleptic properties), compared to autooxidation in the dark at room temperature. The added antioxidants seem to be most efficient in autooxidation conditions, but, from our results, these substances were not able to delay the oxidation of palm olein subjected to sunlight. So, in order to minimize these photooxidative alterations, oils and fats should be kept in the dark at low temperatures in the shops.

\section{Conflict of interest}

Authors have declared no conflicts of interest.

\section{Acknowledgments}

The authors would like to thank the Council of Scientific and Industrial Research, Govt of India and The World Academy of Science (TWAS) who have facilitated financially and logistically the complete realization of this research work in India, under the CSIR 
-TWAS Sandwich Fellowship for Postgraduate Research 2014. The authors also address their thank to the Director of the CSIR-Indian Institute of Chemical Technology, Dr. Srivari Chandrasekhar to have accepted to host this work in His Institution's Laboratories for that fellowship.

\section{References}

Anwar, F., Chatha, S.A.S. and Hussain, A.I. (2007). Assessment of oxidative deterioration of soybean oil at ambient and sunlight storage. Grasas y Aceites, 58(4), 390-395.

AOCS (2003). Official Methods and Recommended Practices of the American Oil Chemists' Society. In Firestone, D. (Ed.) American Oil Chemists' Society, $5^{\text {th }}$ Ed. Champaign, Illinois, USA: AOCS Press.

Bruscatto, M.H., Zambiazi, R.C., Sganzerla, M., Pestana, V.R., Dtero, D., Lima, R. and Paiva, F. (2009). Degradation of tocopherols in rice bran oil submitted to heating at different temperatures. Journal of Chromatographic Science, 47(9), 762-765. https:// doi.org/10.1093/chromsci/47.9.762

Cuppett, S., Schnepf, M. and Hall, C. (1997). Natural antioxidants-Are they a reality". In Shahidi, F. (Ed.). Natural Antioxidants, Chemistry, Health Effects and Applications, p. 12-24. Champaign IL, USA: AOCS Press,

Cuvelier, M.E. and Maillard, M.N. (2012). Stabilité des huiles alimentaires au cours de leur stockage. Oilseeds and fats, Crops and Lipids, 19(2), 125-132. https://doi.org/10.1051/oc1.2012.0440

Djikeng, T.F., Womeni, H.M, Anjaneyulu, E., Boungo, T.G, Karuna, M.S.L., Prasad, R.B.N. and Linder, M. (2017). Performance of Green Tea leaves methanolic extract in stabilizing refined, bleached and deodorized palm olein during storage at frying temperature. European Journal of Nutrition and Food Safety, 7(3), 144-154. https://doi.org/10.9734/ EJNFS/2017/34993

Draper, H.H. and Hadley, M. (1990). Malondialdehyde determination as index of lipid peroxidation. Methods Enzymology, 186, 421-431. https:// doi.org/10.1016/0076-6879(90)86135-I

FAO/WHO. (2009). Report of the $21^{\text {st }}$ session of the Codex Alimentarius Committee on fats and oils. Kota Kinabalu, Malaysia, 16-20 February 2009. Retrieved from FAO website: http://www.fao.org/ tempref/codex/Reports/Alinorm09/al32_17e.pdf

Freja, N., Mozzon, M. and Lercker, G. (1999). Effect of free fatty acids on the oxidative stability of vegetable oil. Journal of the American Oil Chemists' Society, 76(3), 325-329. https://doi.org/10.1007/s11746-999$0239-4$
IDF (1991). International Dairy Federation, IDF-Square Vergote 41. Section 74A. Brussels, Belgium, International IDF Standards.

Iqbal, S. and Bhanger, M.I. (2007). Stabilization of sunflower oil by garlic extract during accelerated storage. Food Chemistry, 100(1), 246-254. https:// doi.org/10.1016/j.foodchem.2005.09.049

Jain, M.R., Sawant, R., Paulmer, R.D.A., Ganguli, D. and Vasudev, G. (2005). Evaluation of thermooxidative characteristics of gear oils by different techniques: Effect of antioxidant chemistry. Thermochimica Acta, 435(2), 172-175. https:// doi.org/10.1016/j.tca.2005.05.016

Kim, N. and Choe, E. (2012). Singlet oxygen-related photooxidative stability and antioxidant changes of diacylglycerol-rich oil derived from mixture of olive and perilla oil. Journal of Food Science, 77(11), C1185-C1190. https://doi.org/10.1111/j.17503841.2012.02928.x

Naz, S., Sheikh, H., Saddiqi, R. and Sayeed, S.A. (2004). Oxidative stability of olive, corn and soybean oil under different conditions. Food Chemistry, 88(2), 253-259.

https://doi.org/10.1016/ j.foodchem.2004.01.042

Ozkan, G., Simsek, B. and Kuleasan, H. (2007). Antioxidant activity of Satureja cilicica essential oil in butter and in vitro. Journal of Food Engineering, 79(4), 1391-1396. https://doi.org/10.1016/ j.jfoodeng.2006.04.020

Pimpa, B., Kanjanasopa, D. and Boolam, S. (2009). Effect of addition of antioxidants on the oxidative stability of refined, bleached and deozorized palm olein. Kasetsart Journal. (Natural Sciences), 43, 370-377.

Raza, A.A., Rashid, A., Qureshi, F.A., Asim, M.F. and William, J. (2009). Analytical investigation of oxidative deterioration of sunflower oil stored under different conditions. Biharean Biologist, 3, 93-97.

Shahidi, F., and Wanasundara, U.N. (2008). Methods for measuring oxidative stability in edible oils. In Akoh, C.C. and Min, D.B. (Eds.), Food Lipids: Chemistry, Nutrition and Biotechnology, p. 387-388. New York: CRC Press. https:// doi.org/10.1201/9781420046649.ch14

Siddhuraju, P. and Becker, K. (2003). Antioxidant properties of various solvent extracts of total phenolic constituents from three different agroclimatic origins of drumstick tree (Moringa oleifera Lam.). Journal of Agricultural Chemistry, 51(8), 2144-2155. https://doi.org/10.1021/jf020444+

Walisiewicz-Niekbalska, W., Kosmacinska, B. and Chmielarz, B. (1997). New trends in the processing 
of vegetable oils and animal fats for technical purposes. Pollena: Tluszcze, Srodki Piorace Kosmet, 41, 190-194.

Womeni, H.M., Tonfack Djikeng, F., Iruku, N.S.S.P., Karuna, M.S.L., Prasad, R.B.N. and Linder, M. (2016). Valorization of soursop flowers (Annona muricata L.) as potent source of natural antioxidants for stabilization of palm olein during accelerated storage. Food Science and Nutrition, 4(6), 1-9. https://doi.org/10.1002/fsn3.349

Womeni, H.M., Tonfack, D.F., Tiencheu, B. and Linder, M. (2013). Antioxidant potential of methanolic extracts and powders of some Cameroonian spices during accelerated storage of soybean oil. Advances in Biological Chemistry, 3, 304-313. https:// doi.org/10.4236/abc.2013.33034 